\title{
Correction to: Predicting Risk for Early Breastfeeding Cessation in Israel
}

\author{
Zarina Paltiel Gabay ${ }^{1} \cdot$ Kaboni Whitney Gondwe $e^{2,3}$ (D) $\cdot$ Maxim Topaz $^{4}$
}

Published online: 7 February 2022

○) Springer Science+Business Media, LLC, part of Springer Nature 2022

Correction to: Maternal and Child Health Journal https://doi.org/10.1007/s10995-021-03292-3

The original version of this article unfortunately contained a mistake.

In the methods section, under sub-heading "Study Design"- the text "XXXX" should be replace with the university name. The correct sentence is given below.

\section{Methods}

\section{Study Design}

This was a descriptive correlational study based on secondary analysis of longitudinal data from the Israeli Center for Disease Control (CDC). This study received institutional ethical review board approval at the University of Haifa, Israel.

Publisher's Note Springer Nature remains neutral with regard to jurisdictional claims in published maps and institutional affiliations.

The original article can be found online at https://doi.org/10.1007/ s10995-021-03292-3.

Zarina Paltiel Gabay

Zpaltiel@bidmc.harvard.edu

Kaboni Whitney Gondwe

gondwe@uwm.edu

Maxim Topaz

mt3315@cumc.columbia.edu

1 School of Nursing, University of Haifa, Haifa, Israel

2 College of Nursing, University of Wisconsin, Milwaukee, USA

3 Center for Advancing Population Science, Medical College of Wisconsin, Milwaukee, USA

4 School of Nursing, Columbia University, New York, USA 